\title{
ANTICORPOS NÃO-HLA REATIVOS CONTRA AS CÉLULAS ENDOTELIAIS PODEM ESTAR ENVOLVIDOS NA PERDA PRECOCE DO ENXERTO RENAL
}

\author{
Non-HLA antibodies reactive against endothelial cells may cause early loss of renal allografts
}

Carla Regina da Silva Correa Ronda ${ }^{1,3}$, Denis Glotz ${ }^{6}$, Daisa Silva Ribeiro David ${ }^{5}$, Luis Estevam lanhez ${ }^{5}$, Hélcio Rodrigues ${ }^{1,2}$, Carlos Sergio Viggiani ${ }^{1,2}$, William Nahas ${ }^{5}$, Elias David-Neto ${ }^{5}$, Maria Cristina Ribeiro de Castro ${ }^{5}$, Jorge Kalil ${ }^{1,2,3,4}$, Nicolas Panajotopoulos ${ }^{1,4}$

\begin{abstract}
RESUMO
Há crescente evidência de que os anticorpos direcionados contra antígenos não-HLA presentes em células endoteliais estão associados à rejeição ao enxerto. Objetivos: 1. Verificar a presença de anticorpos anti-célula endotelial (AACE) nos eluatos de rins nefrectomizados após rejeição mediada por anticorpos não anti-HLA; 2. Verificar a possibilidade de detectar AACE em soros coletados no pré-transplante e antes da rejeição; 3. Verificar o potencial efeito inibitório da IVIG in vitro sobre os AACE. Métodos: Soros (absorvidos com pool de plaquetas) e eluatos provenientes de 12 aloenxertos renais foram testados por citometria de fluxo contra a linhagem EAHy.926 (hibridoma de célula epitelial com célula endotelial). Eluatos positivos foram testados com ou sem adição de imunoglobulina polivalente intravenosa (IVIg). Resultados: A ausência de anticorpos anti-HLA contra o doador foi verificada antes do transplante, da rejeição e antes e depois da transplantectomia, através de provas cruzadas utilizando a técnica de citotoxicidade dependente de complemento (CDC) com e sem anti-globulina humana. Em nove eluatos foram detectados anticorpos reativos contra a linhagem. Em 7/9 casos a marcação de C4d foi negativa. Tais anticorpos não foram detectados no soro pré-transplante. Contudo, 2/4 soros pré-rejeição foram positivos para AACE, e um foi considerado positivo fraco. Em 9 casos, a adição de IVIg resultou em forte diminuição na ligação dos AACE. Conclusões: Os AACE parecem estar envolvidos no processo de rejeição humoral. A detecção de tais anticorpos no soro pré-rejeição abre a possibilidade de um monitoramento imune. A utilização de IVIg para bloqueio da ligação desses anticorpos com a célula-alvo pode funcionar como uma possível terapia na rejeição humoral causada por AACE.
\end{abstract}

Descritores: Rejeição de Enxerto, Células Endoteliais, Anticorpos, Transplante de Rim.

\footnotetext{
Instituição:

1 Laboratório de. Imunologia, InCor; HCFMUSP - São Paulo / SP - Brasil

${ }^{2}$ Laboratório de Histocompatibilidade e Imunologia Celular, LIM 19-HCFMUSP - São Paulo / SP - Brasil

${ }^{3}$ Disciplina de Imunologia Clínica e Alergia, Depto de Clínica Médica, HCFMUSP - São Paulo / SP - Brasil

${ }^{4}$ Instituto de Investigação em Imunologia, Instituto do Milênio - São Paulo / SP - Brasil

${ }^{5}$ Unidade de Transplante Renal, Divisão de Clinica Urológica, HCFMUSP - São Paulo / SP - Brasil

${ }^{6}$ Service de Néphrologie et transplantation, Hospital Saint-Louis, Paris, France
}

Correspondência:

Carla Regina da Silva Corrêa Ronda

Laboratório de. Imunologia, InCor; HCFMUSP - Universidade de São Paulo

Rua Dr. Enéas de Carvalho Aguiar, 44, $9^{\circ}$ andar - CEP 05403-000 - São Paulo / SP - Brasil

Tel: (11) 3069-5903

Fax: (11) 3069-5902

E-mail: cronda51@hotmail.com

Recebido em: 10.10.2007

Aceito em: 04.02.2008

\section{INTRODUÇÃO}

A superfície do endotélio vascular é o primeiro contato entre o sistema imune do receptor e o órgão transplantado, e, em virtude dessa posição anatômica, é considerada um importante alvo no processo de rejeição ao aloenxerto. ${ }^{1} \mathrm{O}$ endotélio vascular tem um papel central na resposta aloimune, uma vez que expressa na sua superficie tanto antígenos do sistema ABO e HLA, quanto antígenos próprios das células endotelias vasculares. ${ }^{2}$ Embora os antígenos HLA expressos nas células endoteliais ativadas do enxerto sejam potenciais alvos da resposta aloimune, a ocorrência de perda precoce do enxerto renal entre irmãos HLA idênticos e até gêmeos com prova-cruzada contra linfócitos negativa sugerem que outros antígenos não-HLA, possam estar envolvidos no processo de rejeição, ${ }^{3,4}$ dentre os quais se destacam os antígenos do sistema endotelial.

No transplante, foi descrito em 1977 pela primeira vez o sistema antigênico expresso nas células endoteliais e monócitos, mas não contra linfócitos, chamado de sistema endotélio-monócito. ${ }^{5}$ A existência desse sistema antigênico não foi confirmada após identificação bioquímica, tendo sido demonstrado mais tarde por outros autores que os anticorpos não-HLA envolvidos na rejeição humoral eram dirigidos contra sítios antigênicos exclusivos das 
células endoteliais não compartilhados por monócitos. A este sistema antigênico deu-se o nome de Sistema VEC (do inglês, Vascular Endothelial Cell System) ${ }^{6}$

Resultados de diferentes estudos têm demonstrado o envolvimento dos anticorpos anti-célula endotelial na rejeição humoral tanto no transplante renal ${ }^{7,8}$ quanto no cardíaco. ${ }^{9}$ Um dos prováveis mecanismos de ação dos anticorpos anti-célula endotelial ocorre através da ligação de tais anticorpos no endotélio dos vasos do enxerto (arteríolas e capilares glomerulares), ativando a via clássica do sistema de complemento, ${ }^{10,11}$ ou ainda por citotoxicidade mediada por células dependentes de anticorpos (ADCC, do inglês antibody dependent cell mediated cytotoxicity).$^{11}$ Apesar de evidências demonstrando o envolvimento dos anticorpos anti-célula endotelial nas rejeições humorais, os mecanismos envolvidos no processo de rejeição causado por esses anticorpos até hoje são extremamente limitados. Além disso, não há informações sobre se esses anticorpos são autoanticorpos ou aloanticorpos, assim como a respeito dos alvos antigênicos por eles reconhecidos. Não há ensaio padrão in vitro capaz de detectar esses anticorpos, uma vez que seu mecanismo de ação ainda não está totalmente definido, dificultando assim o diagnóstico de rejeição causada por estes anticorpos.

O diagnóstico de rejeição mediada por anticorpos apenas com base histológica é difícil, pois até o presente momento nenhuma característica morfológica é patognomônica. As lesões encontradas podem se confundir ou se sobrepor aos achados histológicos de rejeição mediada por célula. Com isso, os episódios de rejeição mediada por anticorpos são freqüentemente subdiagnosticados. ${ }^{12}$

Na busca por entendimento da rejeição mediada por anticorpos, a recente inclusão do marcador C4d na avaliação morfológica de enxertos renais tem emergido como uma importante ferramenta no auxílio ao diagnóstico de rejeição humoral. ${ }^{13} \mathrm{O}$ C4d é um produto da degradação do fator $\mathrm{C} 4$ da via clássica de ativação do sistema de complemento que se liga covalentemente (ligação forte e estável) à superfície da célula endotelial, facilitando sua detecção por imunohistoquímica ou imunofluorescência, e é um indicador indireto da resposta mediada por anticorpos em biópsia renal. ${ }^{14}$

O papel do marcador C4d em rejeições humorais envolvendo os anticorpos anti-célula endotelial é desconhecido, mas seria coerente hipotizar que não pode ser muito valioso, considerando que a maioria desses anticorpos não fixa complemento. ${ }^{15}$

Uma vez que a rejeição humoral é de difícil tratamento, existe grande necessidade de se encontrar uma terapia que possa regular ou eliminar a produção de aloanticorpos de forma segura em certos receptores. Entre as abordagens na tentativa de minimizar este problema, tais como a imunoadsorção com proteína A combinada com drogas citotóxicas e a plasmaferese associada ou não à administração de imunossupressores, foi incluída recentemente a infusão de altas doses de IVIg, que tem se mostrado eficaz no bloqueio dos anticorpos anti-HLA. ${ }^{16}$

A IVIg é um pool de imunoglobulinas humanas do isotipo IgG proveniente de plasma humano de cerca de 10.000 doadores de sangue. ${ }^{17}$ Sua administração tem se mostrado benéfica no tratamento das desordens de imunodeficiência primária há mais de 24 anos, devido a sua propriedade imunomoduladora. ${ }^{18}$ Embora a IVIg tenha múltiplos mecanismos de ação que poderiam ser de benefício na modulação da resposta imune, os mais importantes parecem ser a presença de anticorpos anti-idiotipo, inibição da geração de citocinas inflamatórias, ${ }^{19}$ inibição de injúria mediada por complemento e inibição da produção de anticorpos. ${ }^{19}$

O uso da IVIg associada ou não à plasmaferese tem alcançado eficácia não só no pré-transplante para dessensibilizar pacientes, como também no pós- transplante para reverter rejeição mediada por anticorpos. ${ }^{20}$

O estudo do impacto da IVIg sobre os anticorpos anti-célula endotelial poderia nos fornecer informações muito importantes do ponto de vista terapêutico.

Desta forma, a possível detecção dos anticorpos anti-célula endotelial no soro pré-transplante ou no início da rejeição ao enxerto seria de grande importância na definição de estratégias de prevenção e tratamento das rejeições causadas por estes anticorpos.

\section{OBJETIVOS}

Verificar a presença de anticorpos anti-célula endotelial nos eluatos de rins nefrectomizados após rejeição humoral.

Verificar a possibilidade de detectar os anticorpos anti-célula endotelial em amostras de soros coletadas no pré-transplante e antes da rejeição.

Verificar o potencial efeito inibitório da IVIG in vitro sobre os anticorpos anti- célula endotelial.

\section{MÉTODOS Soros}

Foram estudadas amostras de soro de 12 pacientes que perderam seus enxertos nos primeiros três meses pós-transplante, sendo que 11 foram perdidos por rejeição humoral e um por trombose venosa. Foram excluídos deste estudo casos que apresentaram anticorpos anti-HLA doador específicos nos soros pré- e pós- transplante.

Para detecção dos anticorpos anti-célula endotelial, optamos por fazer inicialmente adsorção dos anticorpos anti-HLA de classe I não doador-específico nas amostras de soro $(1,2,3,5,7,8$ e 11) com pool de plaquetas, com o objetivo de eliminar qualquer reatividade causada por aqueles anticorpos. Para confirmação da eficiência da absorção foi realizado novo PRA-ELISA das amostras absorvidas.

\section{Análise histopatológica}

As análises histopatológicas das biópsias renais foram realizadas no Departamento de Patologia-HC-FMUSP. Foram analisadas 11 biópsias renais, sendo três de biópsia percutânea e oito de rins nefrectomizados: todos os pacientes estavam em uso de imunossupressor até o momento da nefrectomia. As biópsias foram incluídas em bloco de parafina, os quais foram cortados em micrótomo ( $3 \mu$ ), fixadas em lâminas e posteriormente coradas com Hematoxina-Eosina, Tricrômio de Masson, ácido periódico de Schiff (PAS) e PAMS (prata metenamina). O diagnóstico foi estabelecido de acordo com os atuais critérios da Classificação de Banff, ${ }^{21}$ como descrito na Tabela A.

Os dados clinicos e caracteristicas dos pacientes estão descritos na Tabela B. 
Tabela A. Análise histopatológica das biópsias renais.

\begin{tabular}{|c|c|}
\hline Pacientes & Classificação Banff 97 \\
\hline 1 & NC \\
\hline 2 & Banff IIA** \\
\hline 3 & Banff III* \\
\hline 4 & Banff IIB* \\
\hline 5 & CAN $\|^{*}$ \\
\hline 6 & $(\ldots)$ \\
\hline $7 w$ & NC \\
\hline 8 & Banff III** \\
\hline 9 & Banff III* \\
\hline 10 & Banff III* \\
\hline 11 & NC \\
\hline 12 & FT \\
\hline
\end{tabular}

NC: não classificado devido a necrose do parênquima; FT: falha técnica devido a trombose de veia renal; (...): não avaliado; *Biópsia de Rins nefrectomizados; **Biópsia Percutânêa.

\section{Teste de microlinfocitotoxicidade}

Para verificar a presença de anticorpos anti-HLA nas amostras de soro e eluato, foi utilizada técnica de citotoxicidade dependente de complemento (CDC) com e sem anti-globulina humana. Os soros e eluatos foram testados contra linfócitos $\mathrm{T}$ e $\mathrm{B}$ do doador antes e depois do tratamento com ditiotreitol $\left(5 \mathrm{mM}, 30 \mathrm{~min}\right.$ a $\left.37^{\circ} \mathrm{C}\right)$.

\section{Preparação dos eluatos renais}

Os eluatos foram obtidos a partir do tratamento de rins nefrectomizados com acetato de sódio 0,05M, conforme procedimento descrito em $1980 .{ }^{22}$ Os fragmentos de rim foram cortados e lavados extensivamente com tampão Salina Fosfato, até que o sobrenadante ficasse totalmente límpido. Em seguida, os fragmentos foram macerados em um homogeneizador de tecido (Biohomogenizer Biospec). O macerado foi centrifugado sob refrigeração a $4^{\circ} \mathrm{C}$ a 10000 rpm por 20 minutos, por três vezes. Ao final da última lavagem, o sobrenadante foi desprezado e o sedimento ressuspendido em solução de acetato de sódio ( $\mathrm{pH}$ 3.2) por uma hora a $37^{\circ} \mathrm{C}$, sob agitação constante. Em seguida, a solução macerado-acetato foi centrifugada por 20 minutos a $10000 \mathrm{rpm}$ sob refrigeração a $4^{\circ} \mathrm{C}$. $\mathrm{O} \mathrm{pH}$ do sobrenadante (eluato) foi ajustado para $7-7.4$, e foi adicionada azida sódica ( $0,02 \%$ final). O sobrenadante foi dialisado em tampão Salina Fosfato por duas horas, com troca de água a cada 30 minutos e depois concentrado por liofilização. A concentração foi ajustada para $15 \mathrm{mg} / \mathrm{ml}$.

\section{Cultura de linhagem EAHy.926}

A linhagem EAHy.926 é um hibridoma resultante da fusão de HUVEC (do inglês, Human Umbilical Vein Endothelial Cells) com célula epitelial tumoral A549 ${ }^{23}$ cedida gentilmente pelo Prof. Dr. Dennis Glotz do Service de Néphrologie et Transplantation, Hospital SaintLouis, Paris, França. A linhagem foi mantida em cultura com meio DMEM (Life Technologies) suplementado com 150U/ml penicilina/ estreptomicina, 2mM L-glutamine, 10\% SFB, 4500mg/l glicose (Life Technologies) e $0.04 \%$ HAT suplemento (Life Technologies), em garrafas de $250 \mathrm{ml}$, até atingirem a confluência. $\mathrm{O}$ meio foi trocado a cada três ou quatro dias, quando as células foram então submetidas à tripsinização. Para esse procedimento, as células foram inicialmente lavadas com solução de Hanks sem cálcio e magnésio, e em seguida, foram adicionados $5 \mathrm{ml}$ de solução de tripsina (0,1\% em EDTA 0,02\%). Após o descolamento celular (um a dois minutos), foram adicionados imediatamente $10 \mathrm{ml}$ de DMEM com $10 \%$ de SFB. A suspensão celular foi recolhida em tubo de $15 \mathrm{ml}$ e centrifugada por 10 minutos a $1800 \mathrm{rpm}$. O botão celular foi então ressuspendido em $5 \mathrm{ml}$ de DMEM com $10 \%$ de SFB, e a concentração celular foi ajustada para $1 \mathrm{X} 10^{6}$ células/ml e colocadas em novas garrafas para crescimento. Após dois repiques, as células foram utilizadas nos diversos ensaios ou congeladas para uso posterior.

Tabela B. Características e dados clínicos dos pacientes transplantados renais.

\begin{tabular}{|c|c|c|c|c|c|c|c|c|}
\hline \# Pacientes & Sexo & \# Transfusões & \# Gestações & \# Tx & Data Tx & $\begin{array}{c}\text { Duração do } \\
\text { enxerto }\end{array}$ & Tipo doador & Imunossupressão \\
\hline 1 & $\mathrm{~F}$ & 10 & 6 & 1 & $19 / 09 / 00$ & 23 & Falecido & CsA, Pred, MMF \\
\hline 2 & M & 0 & 0 & 1 & $10 / 08 / 01$ & 58 & Falecido & CsA, Pred, MMF \\
\hline 3 & $\mathrm{~F}$ & 0 & 0 & 1 & $11 / 11 / 98$ & 9 & Vivo não parente & CsA, Pred, Aza \\
\hline 4 & M & 0 & 0 & 1 & $20 / 10 / 00$ & 65 & Falecido & CsA, Pred, Aza \\
\hline 5 & M & 1 & 0 & 2 & $20 / 10 / 00$ & 65 & Falecido & CsA, Pred, MMF \\
\hline 6 & M & 0 & 0 & 1 & $11 / 12 / 01$ & 2 & Vivo parente & CsA, Pred, Aza \\
\hline 7 & $\mathrm{~F}$ & 0 & 0 & 2 & 02/09/99 & 15 & Falecido & CsA, Pred, Aza \\
\hline 8 & M & 0 & 0 & 2 & $26 / 07 / 00$ & 10 & Vivo parente & CsA, Pred, MMF \\
\hline 9 & M & 0 & 0 & 1 & $18 / 11 / 96$ & 11 & Falecido & CsA, Pred, Aza \\
\hline 10 & $\mathrm{~F}$ & 0 & 0 & 1 & $15 / 09 / 02$ & 4 & Falecido & FK, Pred, MMF \\
\hline 11 & $\mathrm{~F}$ & 0 & 3 & 2 & 09/12/00 & 4 & Falecido & CsA, Pred, Aza \\
\hline 12 & $M$ & 0 & 0 & 2 & 03/03/04 & 1 & Falecido & CsA, Pred, MMF \\
\hline
\end{tabular}

F: feminino; M: Masculino; Tx: Transplante; CsA: ciclosporina: Pre: prednisona; Aza: azatioprina; MMF: micofenolato mofetil; FK: tacrolimus 


\section{Pesquisa de anticorpos anti-célula endotelial em amostras de soro de indivíduos saudáveis}

Para definição de um pool de soros como controle negativo para posterior análise das amostras de soro e eluato dos pacientes, foram analisadas 15 amostras de soro de indivíduos saudáveis do sexo masculino, não transfundidos quanto à presença de anticorpos de anti-célula endotelial. As amostras foram analisadas por citometria de fluxo e os resultados foram obtidos em mediana de intensidade de fluorescência (MIF). Após ter sido confirmada ausência de anticorpos anti-endotélio nas 15 amostras de soro, foi então feito um pool e utilizado como controle negativo para as amostras de pacientes a serem testadas.

Para determinarmos o valor de corte de reatividade para análise das amostras de soro e eluatos renais, foi utilizada a mediana de intensidade de fluorescência do controle negativo ( pool de soros de indivíduos saudáveis), seguida de dois desvios-padrão tanto para anticorpo do isotipo IgG quanto anticorpo do isotipo IgM.

\section{Detecção de anticorpos anti-célula endotelial por citometria de fluxo}

As células de linhagem EAHy.926 foram distribuídas na concentração de $3 \times 10^{5}$ células/poço em placa de 96 poços com fundos em U. As placas foram centrifugadas a $1800 \mathrm{rpm}$ durante cinco minutos a $4^{\circ} \mathrm{C}$. Os sobrenadantes foram desprezados e os botões celulares foram homogeneizados em um agitador de placas. Em seguida, as células foram incubadas durante 30 minutos a $4^{\circ} \mathrm{C}$ no escuro com $25 \mu$ l de cada soro pré-transplante, pré-rejeição, eluatos, controle negativo ( $p o o l$ de soros de indivíduos saudáveis), controle positivo ( $p o o l$ de soros de pacientes altamente sensibilizados para antígenos HLA) por 30 minutos a $25^{\circ} \mathrm{C}$. Foram pesquisadas as expressões dos antígenos HLA-classe I ( $\beta 2$ microglobulina marcado com FITC diluido1\100), HLA-classe II (HLA DR marcado com FITC diluído 1\50) e antígeno específico de célula endotelial (ECA, a endoglina marcada com FITC diluído $1 \backslash 25)$. Após o período de incubação, as células foram lavadas três vezes em tampão FACS por centrifugação a $1800 \mathrm{rpm}$ durante cinco minutos. Em seguida, foram ressuspensas em $400 \mu \mathrm{l}$ do mesmo tampão e mantidas a $4^{\circ} \mathrm{C}$ até o momento da aquisição. Foi utilizado o programa CellQuest ${ }^{\mathrm{TM}}$ (FASCalibur, Becton\&Dickinson Immunocytometry Systems, San Jose, Califórnia, EUA) para aquisição e análise dos dados. Foram adquiridas 10.000 células na região de interesse (região de células endoteliais) selecionadas por tamanho (FSC, do inglês, forward scatted, dispersão frontal) e granulosidade (SSC, do inglês, side scatted, dispersão lateral) e analisada em mediana de intensidade de fluorescência (MIF).

\section{Teste da ação da IVIg sobre os AACE}

Todos os eluatos considerados positivos para pesquisa de AACE foram retestados com e sem tratamento com IVIg, através de provacruzada por citometria de fluxo. Os eluatos foram diluídos em IVIg (1:2). Cinqüenta microlitros do volume inicial do eluato foram adicionados a igual volume de IVIg $(50 \mathrm{mg} / \mathrm{ml})$ em tubo Fisher, seguidos de incubação por $1 \mathrm{~h}$ a ToA (temperatura ambiente), sob agitação a cada 10min. Como controle, os eluatos foram também diluídos com RPMI (mesma diluição). Os eluatos diluídos (com IVIg e RPMI) foram então retestados para a presença de AACE por citometria de fluxo utilizando a linhagem EAHy.926 como fonte antigênica.

\section{Análise Estatística}

Para análise estatística, foi empregado o Teste de Wilcoxon Sinalizado. A significância estatística foi atribuída para valores do $p$ inferior a $0,05(p<0,05)$.

\section{RESULTADOS}

\section{Análise histopatológica das biópsias renais}

Das 11 biópsias renais reclassificadas, quatro foram biópsias percutâneas e sete de rins nefrectomizados. Nas biópsias percutâneas, um caso foi diagnosticado como Banff IIA, um como Banff III, um como trombose de veia renal e em um caso não foi possível a classificação devido à extensa necrose do parênquima.. Nas biópsias de rins nefrectomizados, dois casos também não foram classificados devido à necrose total do parênquima, três foram classificados como Banff III, um como Banff IIB e um como rejeição crônica II (CAN II, Chronic Allograft Nephropathy II) (Tabela A). Em um caso não foi possível obter o resultado da análise histopatológica por esta ter sido realizada em outro centro.

\section{Pesquisa de anticorpos anti-HLA contra os antígenos HLA do doador}

A pesquisa de anticorpos anti-HLA doador-específicos foi realizada através de provas-cruzadas contra linfócitos T, linfócitos T+AGH e linfócitos B, utilizando as amostras de soro pré-transplante para confirmação de resultados, pré-rejeição e pós-nefrectomia, bem como os eluatos renais.

Nenhuma das amostras (soros e eluatos) foi positiva nas provas-cruzadas, indicando ausência de anticorpos anti-HLA doador-específicos.

\section{Pesquisa de anticorpos anti-célula endotelial em eluatos renais}

Dos 12 eluatos analisados, nove (75\%) foram positivos para presença de AACE do isotipo IgG (eluatos 1, 2, 3 ,4, 5, 6, 7, 8 e 9) (Figura 1), sendo que nos eluatos 4 e 6 , além de IgG foram também detectados anticorpos do isotipo IgM (Figura 2).

Figura 1. Pesquisa de anticorpos anti-célula endotelial isotipo lgG nos eluatos renais por citometria de fluxo. Foi utilizado conjugado anti-IgG-FITC e como fonte de célula endotelial a linhagem EAHy.926 Foram consideradas positivas MIF acima de 148

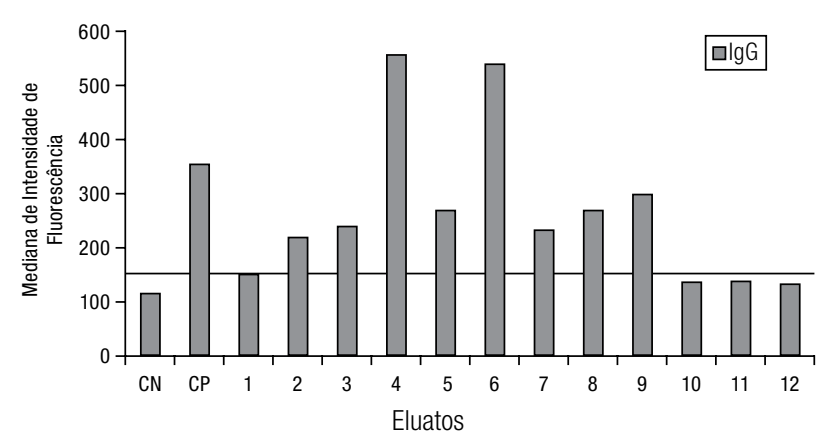

MIF: mediana de intensidade de fluorescência; $C N$ : controle negativo; $C P$ : controle positivo. 
Figura 2. Pesquisa de anticorpos anti-célula endotelial isotipo IgM nos eluatos renais por citometria de fluxo. Foi utilizado conjugado anti IgM-PE e como fonte de célula endotelial a linhagem EAHy.926 Foram consideradas positivas MIF acima 153 para anticorpos do isotipo IgM.

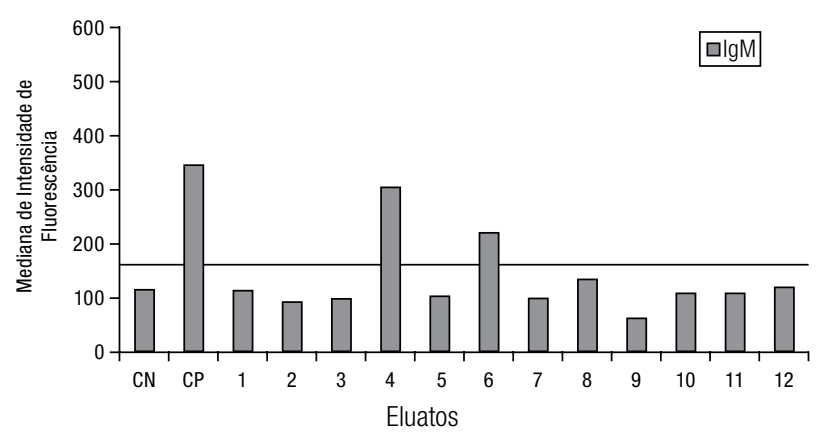

MIF: mediana de intensidade de fluorescência; $C N$ : controle negativo; CP: controle positivo.

\section{Pesquisa de anticorpos anti-célula endotelial no soro pré- transplante e pré-rejeição}

Foram analisados um total de 16 soros: 12 pré-transplante, quatro pré-rejeição (amostras 1, 2, 3 e 9) para verificar a presença de anticorpos do isotipo IgG e/ou IgM . Essa pesquisa foi realizada por citometria de fluxo utilizando como fonte antigênica a linhagem EAHy.926.

Nenhum dos soros pré-transplante foi positivo para anticorpos IgG (Figura 3) e/ou IgM (Figura 4) contra a linhagem endotelial. Já, três dos quatro soros pré-rejeição $(75 \%)$, foram positivos para anticorpos do isotipo IgG (Figura 5), sendo um deles com positividade limítrofe, porém, nenhum dos soros foi positivo para anticorpos do isotipo IgM (Figura 6).

Figura 3. Pesquisa de anticorpos anti-célula endotelial do isotipo lgG em amostras de soros pré-transplante por citometria de fluxo. Foi utilizado conjugado anti-lgG-FITC e como fonte de célula endotelial a linhagem EAHy.926. Foram consideradas positivas MIF acima de 136.

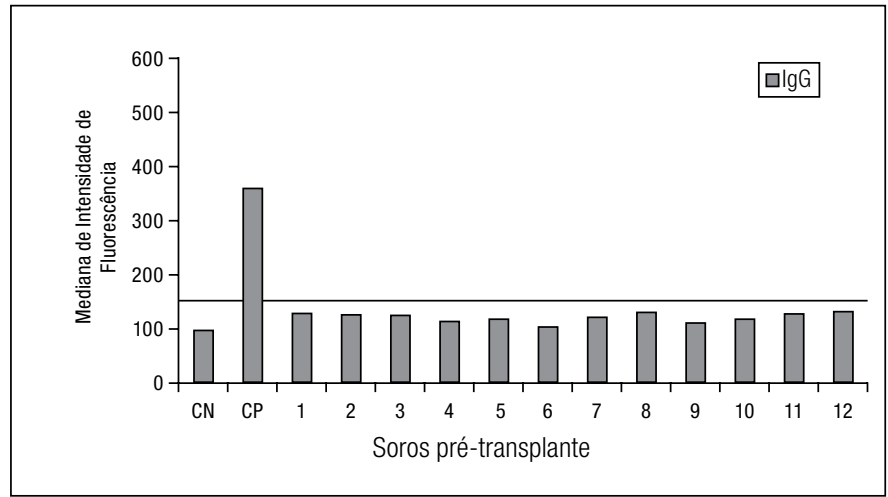

MIF: mediana de intensidade de fluorescência; $C N$ : controle negativo; CP: controle positivo.
Figura 4. Pesquisa de anticorpos anti-célula endotelial do isotipo IgM em amostras de soros pré-transplante por citometria de fluxo. Foi utilizado conjugado anti IgM-PE e como fonte de célula endotelial a linhagem EAHy.926. Foram consideradas positivas MIF acima de 128.

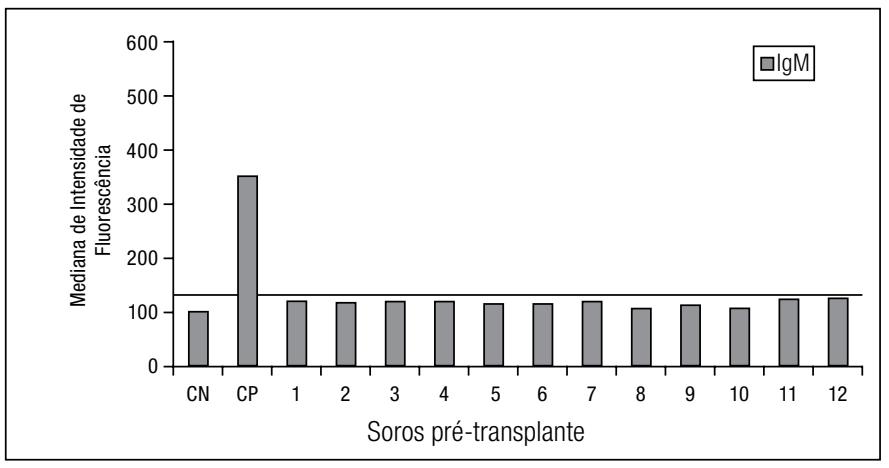

MIF: mediana de intensidade de fluorescência; $C N$ : controle negativo; $C P$ : controle positivo.

Figura 5. Pesquisa de anticorpos anti-célula endotelial do isotipo lgG em amostras de soros pré-rejeição por citometria de fluxo. Foi utilizado conjugado anti-lgG-FITC e como fonte de célula endotelial a linhagem EAHy.926. Foram consideradas positivas MIF acima de 136.

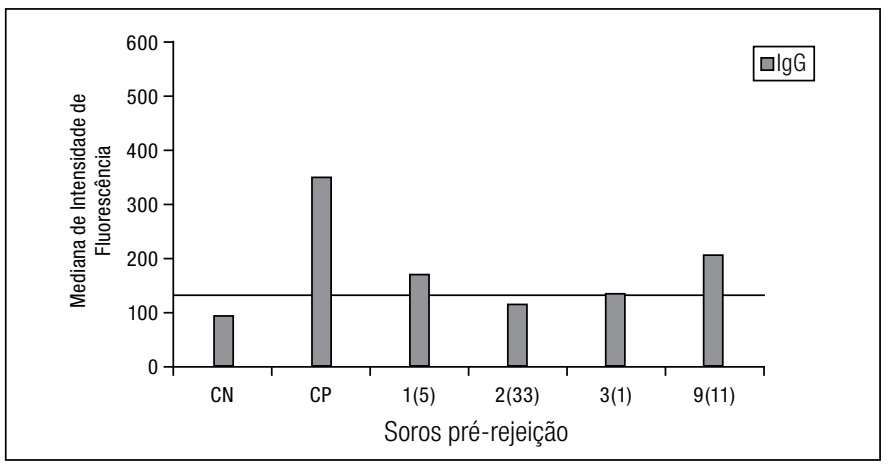

MIF: mediana de intensidade de fluorescência; $C N$ : controle negativo; $C P$ : controle positivo.

( ) : dias antes do diagnóstico de rejeição.

Figura 6. Pesquisa de anticorpos anti-célula endotelial do isotipo IgM em amostras de soros pré-rejeição por citometria de fluxo. Foi utilizado conjugado anti-lgM-PE e como fonte de célula endotelial a linhagem EAHy.926. Foram consideradas positivas MIF acima de 128.

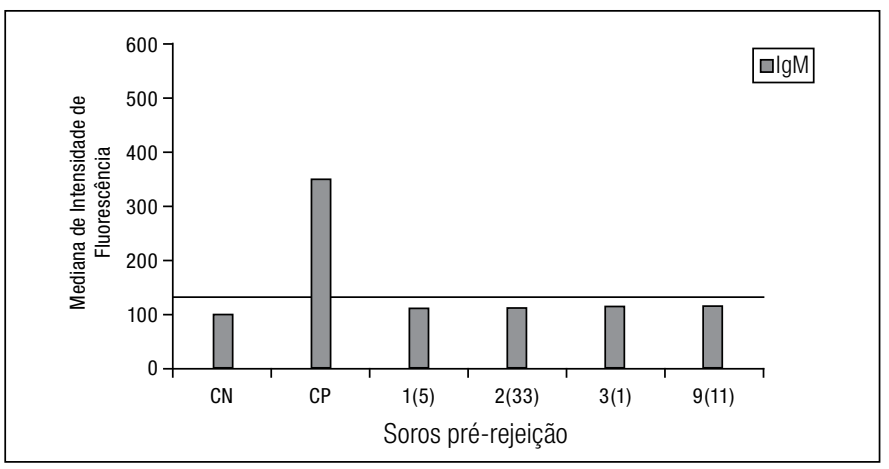

MIF: mediana de intensidade de fluorescência; $C N$ : controle negativo; $C P$ : controle positivo.

( ) : dias antes do diagnóstico de rejeição. 


\section{Efeito da IVIg no bloqueio dos anticorpos anti-célula endotelial}

Para verificar in vitro o efeito da IVIg sobre os anticorpos anti-célula endotelial, foi realizada prova-cruzada por citometria de fluxo dos eluatos que foram positivos contra a linhagem EAHy.926 (2, 3, 4, 5, 6, 7, 8 e 9). Para tanto, os eluatos foram diluidos em 1:2 com IVIg ( $50 \mathrm{mg} / \mathrm{ml}$ final) e RPMI (como controle). Posteriormente, os eluatos e a linhagem EAHy.926 foram incubados por $1 \mathrm{~h} \mathrm{a} \mathrm{T}{ }^{\circ}$. Em todos os oito casos houve significância estatística quando comparados com a diluição 1:2 com IVIg e RPMI $(p<0,012)$ (Figura 7$)$, demostrando que a IVIg tem a capacidade de bloquear a ligação dos AACE na célula-alvo.

Figura 7. Análise por citomeria de fluxo do bloqueio in vitro dos anticorpos anti-célula endotelial presentes nos eluatos renais com o uso da IVIg. Como diluente controle foi utilizado RPMI.

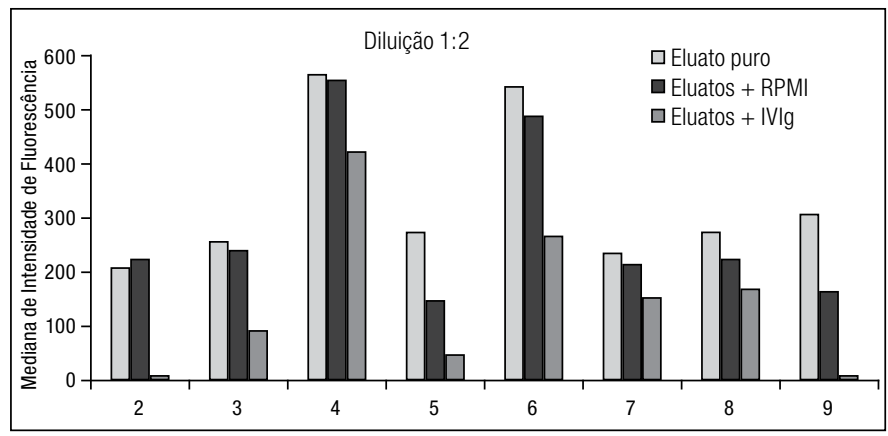

\section{DISCUSSÃO}

Apesar dos avanços alcançados ao longo destes anos no que diz respeito aos métodos de deteç̧ão de anticorpos anti-HLA e ao desenvolvimento de drogas imunossupressoras cada vez mais eficazes e menos nefrotóxicas, o transplante renal ainda é confrontado com problemas de rejeição imunológica. De acordo com a literatura, cerca de 5-8\% dos enxertos renais são perdidos nos dois primeiros meses pós-transplante por mecanismos mediados por anticorpos não detectados pelo teste de citotoxicidade dependente de complemento convencional e nem por técnicas mais sensíveis. ${ }^{24,25}$

Frente à ocorrência de perda precoce do enxerto renal entre irmãos HLA idênticos e até entre gêmeos com prova-cruzada negativa contra linfócitos, avançou-se na hipótese do envolvimento de outros antígenos não-HLA atuando no processo de rejeição, ${ }^{26,27}$ dentre os quais se destaca o sistema endotelial.

Uma das linhas de pesquisa de nosso laboratório foi direcionada ao estudo de resposta humoral contra antígenos de sistemas secundários que pudessem interferir no enxerto, principalmente os do sistema endotelial.

Estudo inicial desenvolvido em nosso centro demonstrou que pode ocorrer rejeição vascular irreversível em pacientes que receberam enxertos provenientes de irmãos gêmeos HLA idênticos com prova cruzada negativa. ${ }^{28}$ Outro estudo realizado por nosso grupo pesquisou o envolvimento de anticorpos anti-célula endotelial em 22 eluatos provenientes de enxertos nefrectomizados após perda da função renal causada por rejeição irreversível. Em oito dos nove $(88,8 \%)$ eluatos provenientes dos enxertos de pacientes com rejeição vascular foram detectados anticorpos do isotipo IgM, que se ligavam às células endoteliais humanas. Portanto, não foram detectados anticorpos anti-células endoteliais nos 13 eluatos perdidos por outros tipos de rejeição.

No presente trabalho foram estudadas amostras de soros dos 12 pacientes que perderam seus enxertos nos primeiros três meses pós-transplante, sendo que 11 foram perdidos por rejeição humoral e um por trombose venosa. Para verificar a presença de anticorpos anti-HLA doador-específicos em soros pré-transplante - para confirmação de resultados prévios, pré-rejeição e pós-nefrectomia, bem como nos eluatos renais, foi realizada prova cruzada contra linfócitos T, T + AGH e linfócitos B. Nenhuma das amostras (soros e eluatos) foi positiva nas provas-cruzadas, indicando ausência de anticorpos anti-HLA doador-específicos e, portanto, o provável envolvimento daqueles anticorpos na perda dos enxertos.

Em nove dos 12 eluatos (75\%) foi detectada forte reatividade contra as células EAHy926, sugerindo claramente o envolvimento de AACE na perda dos enxertos. Nos nove eluatos positivos (1-9), os anticorpos eram do isotipo IgG, sendo que em dois deles (4 e 6) houve participação de AACE do isotipo IgM.

A predominância de anticorpos do isotipo IgG está de acordo com outros estudos associados com rejeição renal..$^{29-32}$ No entanto, outros grupos, ${ }^{33}$ incluindo o nosso, mostraram predomínio de anticorpos do isotipo IgM.

$O$ fato de detectar AACE em eluatos de enxertos com duração de apenas dois dias (caso 6, transplante com doador vivo irmão HLA idêntico) permite elaborar uma hipótese sobre a proposta de Le Bas-Bernadet et al ${ }^{34}$ pelo menos alguns AACE são anticorpos IgM naturais pré-existentes a baixos títulos. Com o contato antigênico após o transplante, pode ocorrer rápido desenvolvimento de anticorpos IgG a alto título, específicos para os antígenos das células endoteliais do enxerto. Com a falta de contato antigênico após a retirada do enxerto, os níveis dos AACE IgG voltam a cair, justificando assim o restrito número de soro pós-nefrectomia reativo contra EAHy926 encontrado. Em apenas três casos foram detectados AACE, sendo que em dois houve coincidência com a reatividade dos respectivos eluatos. Os resultados obtidos com as amostras de soro pré-transplante - todos negativos para AACE também reforçam a nossa hipótese.

Um dado importante deste estudo foi a possível detecção de AACE em três das quatro (75\%) amostras de soro coletadas um, cinco e 11 dias antes do diagnóstico de rejeição. Vale ressaltar que apenas um soro foi negativo na pesquisa de AACE na pré-rejeição, talvez devido a coleta do soro ter sido muito distante do diagnóstico clinico de rejeição (33 dias). Esse dado é de grande valia, inferindo sobre um possível benefício através do monitoramento de pacientes transplantados para detecção de AACE no pós-transplante, e assim, no futuro, delinear estratégias de prevenção e tratamento das rejeições causadas por esses anticorpos.

Em sete dos nove casos foi possível realizar retrospectivamente a pesquisa de C4d. Todos os casos resultaram negativos, sugerindo a participação de anticorpos não fixadores de complemento.

Investigamos também neste trabalho a possibilidade de uma estratégia de prevenção ou reversão de rejeição causada por AACE através de um teste in vitro para verificar o potencial efeito da IVIg sobre aqueles anticorpos.

Para verificar in vitro o efeito da inibição da IVIg sobre anticorpos anticélula endotelial foi realizada prova-cruzada por citometria de fluxo com eluatos previamente diluídos com IVIg e RPMI, como controle. 
Os eluatos positivos contra a linhagem EAHy.926 (2, 3, 4, 5, 6, 7, 8 e 9) foram testados por citometria de fluxo com ou sem adição da IVIg, para verificar sua capacidade de bloquear a ligação dos anticorpos anti-célula endotelial na célula-alvo. Em todos os oito casos, a adição de IVIg in vitro levou a uma forte diminuição da ligação dos anticorpos com a célula-alvo. Esses dados são os primeiros relatos na literatura, mostrando o efeito inibidor da IVIg in vitro sobre a ligação dos AACE com a célula-alvo. A mais provável causa dessa inibição é a presença de anticorpos antiidiotipo na formulação da IVIg. Em todos os oito casos houve significância estatística quando foram comparadas as diluições com IVIg e RPMI, $(p<0,012)$, demonstrando que a IVIg tem capacidade de bloquear a ligação dos AACE na célula-alvo. Para a análise estatística foi empregado o Teste de Wilcoxon Sinalizado. A significância estatística foi atribuída para valores de $p$ inferiores a $0,05(p<0,05)$.

Os dados deste trabalho sugerem que é possível detectar os AACE pelo menos antes do diagnóstico de rejeição, e que o uso de IVIg poderá ser eficaz no tratamento de rejeição causada por esses anticorpos, se os excelentes resultados obtidos in vitro forem confirmados in vivo.

\section{CONCLUSÕES}

Os dados deste trabalho confirmam os achados dos estudos precedentes sobre uma provável participação de AACE na rejeição humoral com perda de enxerto.

É possível detectar esses anticorpos dias antes do diagnóstico clínico da rejeição, avançando a possibilidade de um monitoramento imunológico no pós-transplante para detecção de AACE. Esse monitoramento poderia ser de grande importância para o diagnóstico da rejeição humoral causada por esses anticorpos. Esse tipo de rejeição é de difícil diagnóstico, considerando que os mesmos não são detectados com provascruzadas utilizando linfócitos como fonte antigênica, e pelo menos parte deles não ativa o complemento, não permitindo assim o diagnóstico pelo C4d.

Pela primeira vez na Literatura Internacional foi demonstrado que a adição de IVIg leva ao bloqueio dos AACE com a célula-alvo, abrindo a possibilidade de tratamento da rejeição humoral mediada por esses anticorpos.

\section{ABSTRACT}

There is increasing evidence that antibodies driven against non-HLA antigens of endothelial cells (AECA) are associated to the transplant rejection. Purpose: 1 . To assess the presence of AECA in eluates in kidneys lost from non-HLA antibodies mediated rejection; 2 . To verify the possibility if those AECA could be detected in the pre-transplant and pre-rejection sera; 3 . To verify the potential inhibitory activity of the IVIg on such antibodies. Methods: Platelet-absorbed sera and eluates from 12 renal allografts were tested by flow cytometry against the endothelial/epithelial hybridoma cell line EAHy.926. Positive eluates were then tested with or without the addition of an intravenous polyvalent immunoglobulin preparation (IVIg). Results: The absence of anti-HLA antibodies against the donor was ascertained at the transplant, at rejection, and before and after the transplantectomy by negativity of the cross matches performed using the most sensitive techniques. Antibodies from nine eluates bound to EAHy.926. In seven out of nine cases, the C4d deposition was not found. These AECA were not detected in the pre-transplant sera. However, 2 out of 4 pre-rejection sera were positive for AECA, and one showed a borderline reactivity. In 9 cases, the addition of IVIg led to a strong decrease of AECA the binding. Conclusion: These data showed that AECA may be associated to humoral rejection. The detection of such antibodies in pre-rejection sera opens the possibility of a new immune monitoring. The use of IVIg to block the binding of such antibodies to the target cells can thus offer a potential therapy for humoral rejections.

Keywords: Graft Rejection; Endothelial Cells, Antibodies, Kidney Transplantation

\section{REFERÊNCIAS}

1. Valujskikh A, Heeger PS. Emerging roles of endothelial cells in transplant rejection. Curr opin Immunol. 2003;5:493-8.

2. Rose ML. Endothelial cells as antigen-presenting cells: role in human transplant rejection. Cellular and Molecular Life Sciences. 1998;54:965-78.

3. Carpenter CB. Transplant rejection in HLA identical recipients. Kidney int. 1978;14:283-91.

4. Cerilli GL, Clarke J, Abrams A, Brasile L. Overview; significance of vascular endothelial cell antigen. Transplantation proceedings. 1987;19:4468-70.

5. Moraes JR, Stastny P. A new antigens system exressed human endothelial cells. J Clin Invest. 1977;60:449-54

6. Yard B, Gerritse MS, Claas F, Thorogood J, Bruijn JÁ, Paape ME, et al. The clinical significance of allospecific antibodies against endothelial cells detected with na antibody-dependent cellular cytotoxicity assay for vascular rejection and graft loss after renal transplantation. Transplantation. 1993;55:1287-93.
7. Lucchiari N., N. Panajotopoulos, C. Xu, H. Rodrigues, L.E. Ianhez, J. Kalil, et al., Antibodies eluted from acutely rejected renal allografts bind to and activate human endothelial cells. Hum Immunol. 2000;61(5):518-27.

8. Mohanakumar T, Joyce S, Flye MW.Characterization of kidney cell-specific, non-major histocompatibility complex alloantigen using antibodies eluted from rejeccccted human renal allografts. Transplantation. 1988;46:362-9.

9. Dunn MJ, Crisp S J, Rose ML et al Anti-endothelial antibodies and coronary artery disease after transplantation. Lancet. 1992;339:1566-70

10. Sacks SH, Chowdhury P, Zhou W. Role of the complement systemin rejection. Curr Opin Immunol. 2003;15(5):487-92. Review

11. Rocha PN, Plumb TJ, Crowley SD, Coffman TM: Mechanisms in allograft rejection. Immunol Rev. 2003;196:51-64

12. Nickeleit V, Mihatsch MJ. Kidney transplants, antibodies and rejection: is C4d a magic marker? Nephrol Dial Transplant. 2003 Nov:18(11):2232-9

13. Feucht HE, Schneeberger H, Hillebrand G, Burkhardt K, Weiss M, Riethmuller G, et al. Capillary deposition of C4d complement fragment and early renal graft loss. Kidney international. 1993 Jun;43(6):1333-8. 
14. Herzenber AM, Gill JS, Djurdjev O, Magil AB. C4d deposition in acute rejection: an independent long-term prognostic factor. J Am Soc Nephrol. 2002 Jan;13(1):234-41.

15. Glotz D, Lucchiari N, Pegaz-Fiornet B, Suberbielle-Boissel C. Endothelial cells as targets of allograft rejection. Transplantation. 2006 Jul;15;82(1 Suppl):S19-21.

16. Glotz D, Antoine C, Julia P, Pegaz-Fiornet B, Duboust A, Boudjeltia S, et al. Intravenous immunoglobulins and transplantation for patients with anti-HLA antibodies. Transpl Int. 2004 Jan;17(1):1-8.

17. Kazatchkine MD, Kaveri SV. Immunomodulation of autoimmune and inflammatory diseases with intravenous immune globulin.The New England journal of medicine. 2001 Sep 6;345(10):747-55

18. Ronda N, Kaveri SV, Kazatchkine MD. Treatment of autoimmune diseases with normal immunoglobulin through manipulation of the idiotypic network. Clinical and experimental immunology. 1993 Sep:93 Suppl 1:14-5.

19. Toyoda M, Zhang X, Petrosian A, Galera OA, Wang SJ, Jordan SC. Modulation of immunoglobulin production and cytokine mRNA expression in peripheral blood mononuclear cells by intravenous immunoglobulin. Journal of clinical immunology. 1994 May:14(3):178-89.

20. Glotz D, Antoine C, Duboust A. Antidonor antibodies and transplantation: how to deal with them before and after transplantation. Transplantation. 2005 Feb 15;79(3 Suppl):S30-2

21. Racusen LC, Colvin RB, Solez K, Mihatsch MJ, Halloram PF, Campbell PM, et al. Antibody Mediated Rejection Criteria - an Addition to the Banff 97 Classification of Renal Allograft Rejection. Am J Transplantation. 2003;3:708-14.

22. Claas FHJ, Paul LC, van ES LA, van Rood JJ. Antibodies against donor antigens on endothelial cells and monocytes in eluates of rejected kidney allografts. Tissue. 1980;15(1):19-24.

23. Edgell CJS, McDonald CC, Graham JB. Permanent cell line expressing human factor VII-related antigen established by hybridisation. Proc Natl Acad Sci USA. 1983;80:3734-7.

24. Crespo M, Pascual M, Tolkoff-Rubin N, Mauiyyedi S, Collins AB, Fitzpatrick D, et al. Acute humoral rejection rejection in renal allograft recipients: I. Incidence, serology and clinical characteristics. Transplantation. 2001 Mar 15;71(5):652-8.
25. Gupta RK, Nampoory MR, Johny KV, Costandi JN, Nair MP, Francis I, et al. Successful therapy of acute vascular rejection with combined plasma-exchange and monoclonal antibody. Transplantation proceedings. 2001 Aug;33(5):2770-3.

26. Suberbielle-Boissel C, Legendre C, Kssentini M, Kreis H, Charron D, Raffoux C. Anti-endothelial and epithelial antibodies in renal transplantation. Transplantation proceedings. 1998 Sep;30(6):2852.

27. Sumitran-Karuppan S, Tyden G, Reinholt F, Berg U, Moller E. Hyperacute rejections of two consecutive renal allografts and early loss of the third transplant caused by non-HLA antibodies specific for endothelial cells. Transplant immunology. 1997 Dec;5(4):321-7.

28. Kalil J, Guilherme L, Neumann J, Rosales C, Marin M, Saldanha L, et al. Humoral rejection in two HLA identical living related donor kidney transplants. Transplantation proceedings. 1989 Feb;21(1 Pt 1):711-3

29. Jordan SC, Yap HK, Sakai RS, Alfonso P, Fitchman M. Hyperacute allograft rejection mediated by anti-vascular endothelial cell antibodies with a negative monocyte crossmatch. Transplantation. 1988 Oct;46(4):585-7.

30. Ferry BL, Welsh KI, Dunn MJ, Law D, Proctor J, Chapel H, et al. Anti-cell surface endothelial antibodies in sera from cardiac and kidney transplant recipients: association with chronic rejection. Transplant immunology. 1997 Mar;5(1): 17-24.

31. Mathew JM, Joyce S, Lawrence W, Mohanakumar T. Evidence that antibodies eluted from rejected kidneys of HLA-identical transplants define a non-MHC alloantigen expressed on human kidneys. Transplantation. 1991 Sep;52(3):559-62.

32. Perrey C, Brenchley PEC, Johnson RWG and Martin S. An association between antibodies specific for endothelial cells and renal transplant failure. Transplant Immunology. 1998;6:101-6.

33. Crisp SJ, Dunn MJ, Rose ML, Barbir M, Yacoub MH. Antiendothelial antibodies after heart transplantation: the accelerating factor in transplant-associated coronary artery disease? J Heart Lung Transplant. 1994 Jan-Feb;13(1 Pt 1):81-91;discussion-2.

34. Bas-Bernard, Hourmant M, Coupel S, Bignon JD, Soulilou JP, Charreau B. NonHLA-type endothelial cell reactive alloantibodies in pre-transplant sera of kidney recipients trigger apoptosis. Am J Transplantation. 2003;3:167-77. 